ORIGINAL ARTICLE

\title{
Expression of apoptosis related proteins during malignant progression in chronic ulcerative colitis
}

\author{
C J van der Woude, H Moshage, M Homan, J H Kleibeuker, P L M Jansen, H van Dekken
}

J Clin Pathol 2005;58:81 1-814. doi: 10.1136/icp.2004.017418

See end of article for authors' affiliations

....................

Correspondence to: $\mathrm{Dr} C \mathrm{~J}$ van der Woude, Department of

Gastroenterology and Hepatology, Erasmus MC/ University Medical Centre, Rotterdam, PO Box 2040, 3000 CA Rotterdam, The Netherlands; c.vanderwoude@ erasmusmc.nl

Accepted for publication 21 December 2004

\begin{abstract}
Background: Chronic ulcerative colitis (CUC) is associated with increased risk of developing colon cancer through a dysplasia (intraepithelial neoplasia)-carcinoma sequence.

Aims: To investigate the expression of apoptosis and inflammatory related proteins in CUC.

Methods: The expression of proteins involved in apoptosis and inflammation (inducible nitric oxide synthase (iNOS), cyclooxygenase 2 (COX-2), Bcl-xl, Fas, and active caspase 3) was investigated and compared with that seen in sporadic colon carcinoma.

Results: COX-2 was negative in the epithelium of all samples. iNOS was clearly present in inflammatory areas in CUC epithelium, weakly expressed in dysplasia, and absent or weakly expressed in tumour cells. Bcl-xl was absent in CUC, increased in dysplasia, and highly expressed in most carcinomas. Fas expression was positive in the surface epithelium of CUC, dysplasia, and most tumour cells. Activated caspase 3 was weakly positive in all samples, indicating limited apoptosis. Compared with CUC associated carcinoma, iNOS was consistently expressed in sporadic colon carcinoma cells, whereas Bcl-xl was almost absent in these tumour cells and Fas was only weakly expressed. Activated caspase 3 was present in normal mucosal samples and some tumour cells.

Conclusion: Apoptosis related proteins-particularly iNOS, Bcl-xl, and Fas-show a distinct pattern of expression in the CUC to carcinoma sequence, which differs from that seen in sporadic carcinoma, but bears a striking resemblance to that seen during neoplastic progression in Barrett's oesophagus. These results support a causal role for chronic inflammation in cancer development in CUC, and treatment of ulcerative colitis should aim to minimise inflammation.
\end{abstract}

C hronic ulcerative colitis (UC) is associated with an increased risk of malignancy that develops through a dysplasia-carcinoma sequence. ${ }^{1}$ Dysplasia (intraepithelial neoplasia) is present in more than $70 \%$ of patients with chronic UC and cancer, and it coincides with the location of the cancer, which arises from chronically inflamed mucosa. ${ }^{2}{ }^{3}$ Dysplastic areas are often difficult to recognise on endoscopy. They may appear to be flat or only slightly raised above the level of the mucosa. Dysplasia may also occur within or near raised plaque-like lesions, nodules, polyps, or masses, in which case the term dysplasia associated lesion or mass is used. Strong support exists for a link between chronic inflammation and the development of cancer in the gastrointestinal tract. ${ }^{45}$ During inflammation, the activation of the transcription factor nuclear factor $\kappa \mathrm{B}(\mathrm{NF}-\kappa \mathrm{B})$ induces the expression of many genes involved in cell survival, including antiapoptotic genes. ${ }^{56}$ Continuously increased expression of antiapoptotic proteins endows cells with a survival and proliferation advantage and may facilitate the appearance of tumour cells. Previously, we have studied the expression of the inflammation activated, NF- $\kappa \mathrm{B}$ regulated proteins inducible nitric oxide synthase (iNOS) and cyclooxygenase 2 (COX-2) in the gastritis-metaplasia-gastric cancer sequence and in the metaplasia-dysplasia-adenocarcinoma sequence in Barrett's oesophagus. ${ }^{7}$ Nitric oxide, produced by iNOS, has been shown to inhibit apoptosis by inhibiting caspase activity, although chronic exposure to high concentrations of nitric oxide can also promote apoptosis. ${ }^{8} \mathrm{COX}-2$ inhibition prevents cell proliferation and promotes apoptosis, and is being considered as a chemopreventive strategy in colon cancer. ${ }^{9}$ In addition to changes in the expression of NF- $\kappa \mathrm{B}$ regulated antiapoptotic proteins, tumour cells often show more permanent changes in the expression of other apoptosis related proteins, such as death receptors (Fas) and Bcl-2 family members. The Bcl-2 family of proteins plays a key role in apoptosis by determining the susceptibility of the mitochondrial outer membrane to pore formation. Leakage of mitochondrial proteins through these pores into the cytoplasm constitutes a strong apoptotic signal.

"Continuously increased expression of antiapoptotic proteins endows cells with a survival and proliferation advantage and may facilitate the appearance of tumour cells"

Despite knowledge about the use of different genetic markers in detecting colitis associated neoplasia, the pathogenesis of colon cancer in chronic UC is still poorly understood, but there are indications that the pathogenesis is different from that of sporadic colon cancer, namely: (1) dysplasia in UC is preceded by a long history of chronic inflammation and can be seen at sites distant from the cancer, whereas dysplasia in sporadic colon cancer is usually associated with a discrete polyp without inflammation. (2) Mutations in the ras protooncogene are present in 40-60\% of sporadic colon cancers and are probably an early event; in contrast, in cancer associated with UC, these mutations are less frequently seen and are probably a late event. ${ }^{10-12}$ (3) Loss of heterozygosity $(\mathrm{LOH})$ of the p53 gene and src activation occur in UC non-dysplastic epithelium, UC associated dysplasia, and in UC associated carcinoma, whereas there is an absence of $\mathrm{LOH}$ of p53 in regions with negative, indefinite,

Abbreviations: COX-2, cyclooxygenase 2; iNOS, inducible nitric oxide synthase; $\mathrm{LOH}$, loss of heterozygosity; NF- $\mathrm{kB}$, nuclear factor $\kappa B$; UC, ulcerative colitis 
or low grade dysplastic histology. ${ }^{13}$ (4) LOH at the APC loci in UC was noted in dysplasia with associated carcinoma, but $\mathrm{LOH}$ of APC was not present either in cases of non-dysplastic epithelium or in high grade dysplasia alone. Conversely, LOH of APC was present in four of 19 colonic adenomas. ${ }^{14} 15$

The aim of our study was to determine the expression pattern of the NF- $\kappa \mathrm{B}$ regulated antiapoptotic proteins iNOS and COX-2, the death receptor Fas, and the antiapoptotic Bcl2 family member Bcl-xl in the sequence chronic UC to chronic UC associated carcinoma. Furthermore, this expression pattern was compared with that seen previously in the sequence from Barrett's oesophagus to Barrett's oesophagus associated adenocarcinoma and with that seen in sporadic colon carcinoma.

\section{MATERIALS AND METHODS}

\section{Patient selection and tissue collection}

Tissue samples were available from five patients who participated in an endoscopy surveillance programme between January 1990 and December 2002 at the Erasmus MC University Hospital, Rotterdam, the Netherlands because of longstanding colitis and who underwent colectomy for colitis associated carcinoma. In addition, tissue samples were available from four patients who underwent colectomy because of sporadic colon carcinoma. This group was extended with 10 additional samples, stained only for Fas and Bcl-xl. Histology was performed on samples stained with haematoxylin and eosin, and samples were scored for the presence and degree of inflammation and dysplasia and the presence of adenocarcinoma. The classification of dysplasia was performed as proposed by Riddell et al, ${ }^{16}$ and scored by two pathologists. Low grade dysplasia was excluded from our study.

\section{Immunohistochemical analysis}

All staining procedures were performed on $4 \mu \mathrm{m}$ thick, formalin fixed, dewaxed sections. Table 1 provides details of the immunohistochemical protocols.

\section{Immunoreactivity scores}

After staining, the immunohistochemical sections were scored by two different observers for the percentage of positively stained epithelial cells and tumour cells. The intensity was not scored, because of the different immunostaining characteristics of the antibodies. If there were differences in interpretation, the sample was scored again and a consensus was reached. No staining of epithelial/ tumour cells was scored as $0 ; 0-10 \%$ of stained epithelial/ tumour cells was scored as $1 ; 11-50 \%$ was scored as 2 ; and $51-100 \%$ was scored as 3 . Active caspase 3 was scored as positive or negative in epithelial cells and tumour cells.
Table 2 Immunohistochemical staining results of the ulcerative colitis group

\begin{tabular}{|c|c|c|c|c|c|}
\hline & iNOS & cox-2 & Fas & Bcl-xl & Active caspase 3 \\
\hline \multicolumn{6}{|l|}{ Patient A } \\
\hline UC & 0 & 0 & 1 & 0 & Positive \\
\hline Dysplasia & 3 & 0 & 3 & 2 & Positive \\
\hline $\mathrm{Ca}$ T3N2MO & 1 & 0 & 3 & 3 & Positive \\
\hline \multicolumn{6}{|l|}{ Patient B } \\
\hline UC & 0 & 0 & 1 & 0 & Positive \\
\hline Dysplasia & 1 & 0 & 2 & 2 & Positive \\
\hline Ca T3N1MO & 1 & 0 & 3 & 2 & Positive \\
\hline \multicolumn{6}{|l|}{ Patient C } \\
\hline UC & 0 & 0 & 1 & 0 & Positive \\
\hline Dysplasia & 1 & 0 & 1 & 1 & Positive \\
\hline Ca in situ TIS & 0 & 0 & 0 & 1 & Positive \\
\hline \multicolumn{6}{|l|}{ Patient D } \\
\hline UC & 0 & 0 & 1 & 0 & Positive \\
\hline Dysplasia & 1 & 0 & 3 & 1 & Positive \\
\hline Ca TINOMO & 1 & 0 & 3 & 3 & Positive \\
\hline \multicolumn{6}{|l|}{ Patient $\mathrm{E}$} \\
\hline UC & 0 & 0 & 1 & 0 & Positive \\
\hline Dysplasia & 3 & 0 & 2 & 1 & Positive \\
\hline $\mathrm{Ca}$ T2N1MO & 0 & 0 & 3 & 3 & Positive \\
\hline
\end{tabular}

Immunohistochemical score: 0, 0\%; 1, 0-10\%; 2, 10-50\%; 3, 50-100\%. $\mathrm{Ca}$, carcinoma; COX-2, cyclooxygenase 2 ; iNOS, inducible nitric oxide synthase; UC, ulcerative colitis.

\section{RESULTS}

\section{Characteristics of patients with UC}

All five patients (three male) were the subject of surveillance colonoscopies because of longstanding colitis (mean, 15 years) and four of five were using immunosuppressives (three cyclosporine and one methotrexate). Colectomy was performed in all patients because of cancer at a mean age of 50 years. The mean time to develop dysplasia/adenocarcinoma in this group was 16 years from the time of first diagnosis of colitis. In all cases, the carcinoma was well differentiated.

\section{Immunohistochemical staining of UC associated dysplasia and cancer}

Tables 2 and 3 present an overview of all the immunohistochemical results.

In the epithelium of chronic UC, iNOS staining was positive in areas of inflammation and negative in areas without inflammation (fig 1A). In dysplasia, the iNOS score was 1 in three of five patients and 3 in two of five patients (fig 1B). iNOS staining in tumour cells was scored 0-1 (fig IC). COX-2 was negative in the epithelium of all samples but clearly positive in lamina propria immune cells, which served as an internal control. The Fas expression score was 1 in the surface epithelium of chronic UC. In dysplasia, the mean epithelial Fas expression score was 2 (fig lD). In four of

Table 1 Immunohistochemical staining methods

\begin{tabular}{|c|c|c|}
\hline Protein & Antigen retrieval & Primary antibody \\
\hline iNOS & $\begin{array}{l}2 \times 15 \text { minutes at } 98^{\circ} \mathrm{C} \text { in } 1 \mathrm{mM} \text { EDTA; } \\
\mathrm{pH} 8.0\end{array}$ & $\begin{array}{l}\text { Mouse monoclonal at 1/100 dilution; BD-Transduction Laboratories, San Jose, } \\
\text { California, USA; catalogue no. } 610431\end{array}$ \\
\hline $\operatorname{cox}-2$ & $\begin{array}{l}\mathrm{MW} ; 2 \times 15 \text { minutes at } 98^{\circ} \mathrm{C} \text { in } 1 \mathrm{mM} \text { EDTA; } \\
\mathrm{pH} 8.0\end{array}$ & $\begin{array}{l}\text { Mouse monoclonal at } 1 / 50 \text { dilution; BD-Transduction Laboratories; catalogue no. } \\
610203\end{array}$ \\
\hline Fas & $\begin{array}{l}\mathrm{MW} ; 2 \times 15 \text { minutes at } 98^{\circ} \mathrm{C} \text { in } 10 \mathrm{mM} \text { citrate; } \\
\mathrm{pH} 6.0\end{array}$ & $\begin{array}{l}\text { Mouse monoclonal at 1/400 dilution; Upstate Biotechnology, Lake Placid, } \\
\text { Massachusetts, USA; catalogue no. 05-201 }\end{array}$ \\
\hline $\mathrm{Bcl}-\mathrm{xl}$ & $\begin{array}{l}\mathrm{MW} ; 2 \times 15 \text { minutes at } 98^{\circ} \mathrm{C} \text { in } 0.1 \mathrm{M} \mathrm{Tris} / \mathrm{HCl} \text {; } \\
\mathrm{pH} 9.0\end{array}$ & $\begin{array}{l}\text { Mouse monoclonal at } 1 / 100 \text { dilution; Zymed Laboratories, South San Francisco, } \\
\text { California, USA; cat. no. } 33-6300\end{array}$ \\
\hline Active caspase 3 & $\begin{array}{l}\text { MW }(700 \mathrm{~W}) ; 1 \times 8 \text { minutes in } 10 \mathrm{mM} \text { citrate } \\
\text { buffer; } \mathrm{pH} 6.0\end{array}$ & $\begin{array}{l}\text { Rabbit polyclonal at 1/100 dilution; Cell Signaling Technology, Beverley, } \\
\text { Massachusetts, USA; catalogue no. } 9661 \mathrm{~S}\end{array}$ \\
\hline
\end{tabular}


Table 3 Immunohistochemical staining results of the sporadic colon carcinoma group

\begin{tabular}{|c|c|c|c|c|c|}
\hline & iNOS & cox-2 & Fas & Bcl-xl & Active caspase 3 \\
\hline \multicolumn{6}{|l|}{ Patient A } \\
\hline Normal mucosa & 1 & 0 & 1 & 1 & Positive \\
\hline $\mathrm{Ca}, \mathrm{T} 3 \mathrm{~N} 1 \mathrm{MO}$ & 2 & 1 & 1 & 0 & Positive \\
\hline \multicolumn{6}{|l|}{ Patient B } \\
\hline Normal mucosa & 1 & 1 & 1 & 1 & Positive \\
\hline $\mathrm{Ca}, \mathrm{T} 3 \mathrm{~N} O \mathrm{MO}$ & 2 & 2 & 1 & 0 & Positive \\
\hline \multicolumn{6}{|l|}{ Patient C } \\
\hline Normal mucosa & 1 & 1 & 1 & 0 & Positive \\
\hline $\mathrm{Ca}, \mathrm{T} 3 \mathrm{~N} O \mathrm{MO}$ & 3 & 1 & 1 & 0 & Positive \\
\hline \multicolumn{6}{|l|}{ Patient D } \\
\hline Normal mucosa & 1 & 1 & 1 & 1 & Positive \\
\hline $\mathrm{Ca}, \mathrm{T} 3 \mathrm{~N} 2 \mathrm{MO}$ & 1 & 0 & 1 & 0 & Positive \\
\hline $\begin{array}{l}\text { Immunohistochemic } \\
\mathrm{Ca} \text {, carcinoma; CO } \\
\text { synthase. }\end{array}$ & $\begin{array}{l}\text { score } \\
-2, \text { cy }\end{array}$ & $\begin{array}{l}0 \% ; 1 \\
\text { oxygen }\end{array}$ & $0-10$ & $\begin{array}{l}2,10 \\
\text { NOS, in }\end{array}$ & $\begin{array}{l}-50 \% ; 3,50-100 \% \\
\text { ducible nitric oxide }\end{array}$ \\
\hline
\end{tabular}

five cancers the tumour cells scored 3 for Fas expression (fig $1 \mathrm{E}$ ).

Bcl-xl was not expressed in chronic UC, but it was expressed in dysplasia (score, 1-2) (fig $1 \mathrm{H}$ ) and the tumour cells of all but one cancer (score, 3) (fig 1F). Activated caspase 3 was weakly positive in all samples, indicating only limited ongoing apoptosis (fig $1 G$ ).

\section{Immunohistochemical staining of sporadic colon carcinoma}

Patients were all male with a mean age of 63 years at the time of diagnosis. All four sporadic carcinomas were well differentiated. Table 3 shows the he TNM classification of the tumours, together with the immunohistochemical staining results for the tumour samples and normal mucosa obtained from the resection material.
The iNOS staining score was 1 in all normal mucosal samples and $1-2$ in tumour cells (fig $1 \mathrm{H}$ ). In the normal mucosa of the resected large bowel, staining for COX-2 was seen in some epithelial cells and lamina propria immune cells. The COX-2 staining score ranged from 0 to 2 in tumour cells. In normal mucosa, the Fas expression score was 1 in the surface epithelium and some tumour cells were also positive (score 1; fig 1I). Bcl-xl in normal mucosa samples scored 0-1 and was absent in tumour cells (score 0) (fig $1 \mathrm{~J}$ ). Activated caspase 3 was positive in both the normal mucosal samples and in tumour cells (fig $1 \mathrm{~K}$ ). Because of the differences in Fas and Bcl-xl expression between the two groups, we analysed 10 additional sporadic carcinomas for Fas and Bcl-xl staining. In normal mucosa, epithelial Fas scored 0-1, whereas the Fas staining score in tumour cells of sporadic carcinoma was 0 in two of 10 samples, one in six of 10 samples, and 2 in two of 10 samples. The Bcl-xl score was 0-1 in both the additional normal mucosa samples and the sporadic colon carcinoma cells.

\section{DISCUSSION}

In our present study, we found increased expression of iNOS in UC associated dysplasia, whereas iNOS expression was absent in UC associated carcinoma. In contrast, Bcl-xl expression was absent in chronic UC, but was clearly positive in tumour cells. This bears a striking similarity to the expression pattern seen for antiapoptotic proteins in Barrett's oesophagus associated adenocarcinoma. ${ }^{5}$ In the sequence leading to Barrett's associated adenocarcinoma, iNOS is expressed in the early stage of intestinal metaplasia, although the tumour cells themselves do not express iNOS. Similarly, the antiapoptotic Bcl-2 family member Bcl-xl was almost absent in the early stages leading to Barrett's associated adenocarcinoma, but was strongly expressed in tumour cells. Similar to the expression pattern seen in the Barrett's
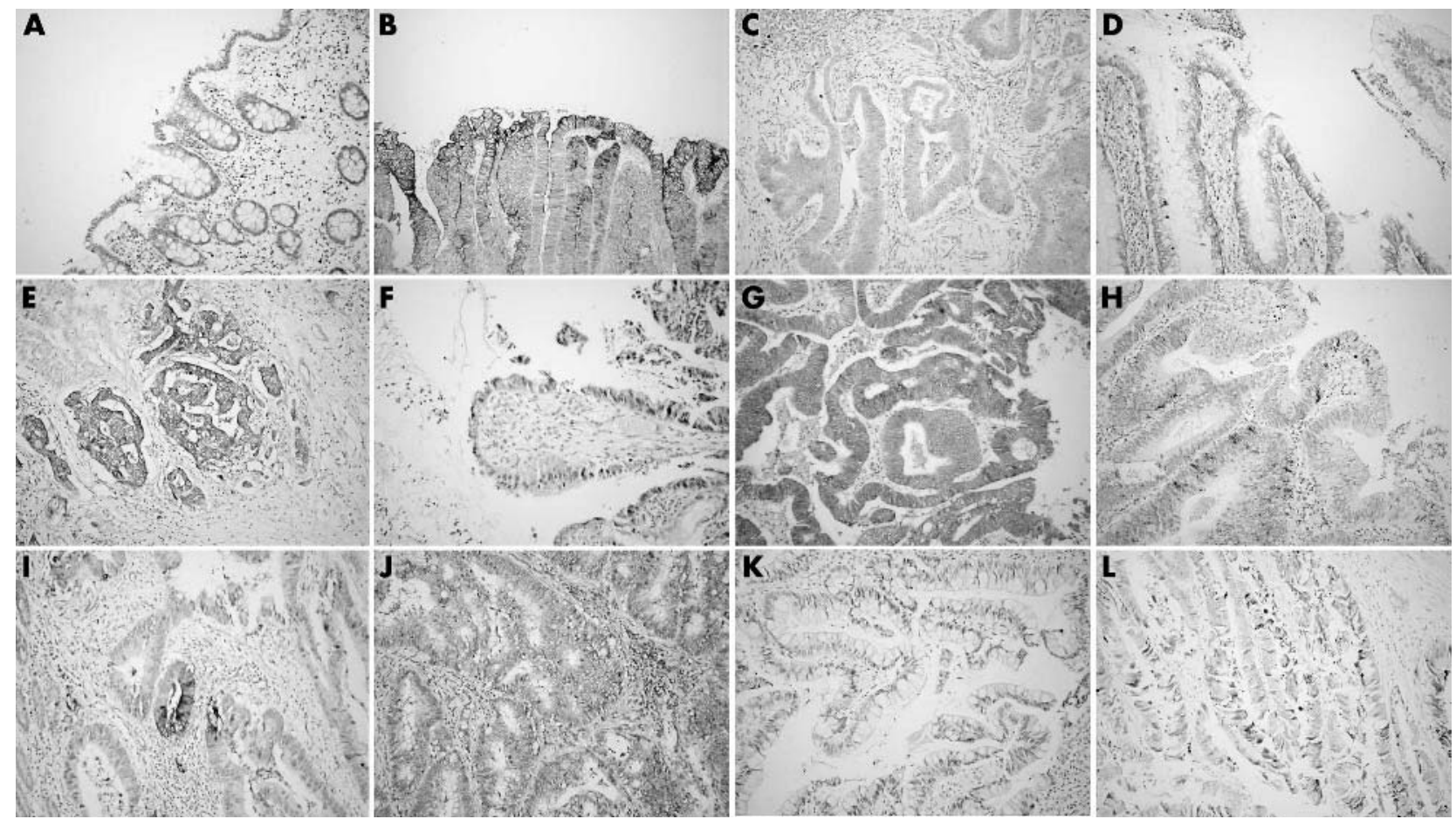

Figure 1 (A) Absence of inducible nitric oxide synthase (iNOS) expression in chronic ulcerative colitis. (B) iNOS expression is present in epithelial cells in dysplasia. (C) Absence of iNOS expression in tumour cells. (D) Fas is expressed in epithelial cells in dysplasia. (E) Fas is strongly expressed in tumour cells. (F) Bcl-xl is expressed in epithelial cells in dysplasia. (G) Bcl-xl is expressed in tumour cells. (H) Caspase 3 is activated in epithelial cells in dysplasia. (I) iNOS is expressed in tumour cells of sporadic adenocarcinoma. (J) Fas is weakly expressed in sporadic colon carcinoma tumour cells. (K) Absence of Bcl-xl expression in sporadic colon carcinoma cells. (L) Caspase 3 is activated in sporadic colon cancer tumour cells. 


\section{Take home messages}

- There was a distinct pattern of expression of apoptosis related proteins -in particular, inducible nitric oxide synthase, Bcl-xl, and Fas-in the sequence from chronic ulcerative colitis to carcinoma

- This pattern differs from that seen in sporadic carcinoma and bears more resemblance to the sequence of events seen in the development of Barrett's adenocarcinoma

- These results support a causal role for chronic inflammation in the development of cancer in chronic ulcerative colitis and we suggest that inflammation should be minimised in this disease

sequence, COX-2 expression was absent from the epithelium at all stages, except that in Barrett's associated adenocarcinoma COX-2 expression was seen in a few of the tumour cells. Both chronic UC associated carcinoma and Barrett's associated adenocarcinoma develop from inflamed mucosa, and it is therefore tempting to speculate that common mechanisms, related to the continuous induction of NF- $\mathrm{KB}$ regulated antiapoptotic proteins, contribute to the malignant progression in these disorders. Therefore, a strong recommendation for the prevention of cancer in chronic UC would be to minimise inflammation in the colon of affected patients. According to our findings, the use of COX-2 inhibitors as a chemopreventive strategy would not be effective.

"The differential expression of Fas and $\mathrm{Bcl}-\mathrm{xl}$ could be used to distinguish chronic ulcerative colitis associated premalignant lesions from sporadic adenomas, and thus prevent unnecessary colectomy"

Although our study was not meant to be an exhaustive and systematic comparison between UC associated carcinoma and sporadic carcinoma, we did note interesting differences in the expression of Fas and Bcl-xl between tumour cells in UC associated carcinoma and tumour cells in sporadic carcinoma. Fas was strongly expressed in most UC associated dysplasia and tumour cells, whereas it was weakly expressed in tumour cells of the sporadic carcinomas. Furthermore, Bcl$\mathrm{xl}$ was clearly expressed in chronic UC tumour cells, but showed only weak staining in sporadic colon cancer cells. Because high grade dysplasia is an indication for colectomy, whereas sporadic adenomas may be removed endoscopically, even if they occur in an area histologically involved with colitis, the differential expression of Fas and Bcl-xl could be used to distinguish chronic UC associated premalignant lesions from sporadic adenomas, and thus prevent unnecessary colectomy. The different expression patterns of proapoptotic and antiapoptotic proteins did not result in differences in apoptosis. Activated caspase 3, used as a marker of apoptosis, was weakly present in both chronic UC associated colon cancer and sporadic colon cancer, and may be the result of increased apoptosis in the presence of increased (tumour) cell proliferation.

In conclusion, we saw a distinct pattern of expression of apoptosis related proteins in the sequence from chronic ulcerative colitis to carcinoma. This pattern differs from the one seen in sporadic carcinoma and bears more resemblance to the sequence of events seen in Barrett's adenocarcinoma. Our results support a causal role for chronic inflammation in the development of cancer in chronic UC and therefore we propose to minimise inflammation in UC.

\section{Authors' affiliations}

C J van der Woude, Departments of Gastroenterology and Hepatology, Erasmus MC, PO Box 2040, 3000 CA Rotterdam, The Netherlands H Moshage, M Homan, J H Kleibeuker, University Hospital Groningen, 9713 GZ Groningen, The Netherlands

P L M Jansen, Academic Medical Centre, 1100 DD Amsterdam, The Netherlands

H van Dekken, Department of Pathology, Erasmus MC

\section{REFERENCES}

1 Goldman H. Significance and detection of dysplasia in chronic colitis. Cancer 1996:78:2261-3.

2 Lennard-Jones JE, Nelville DM, Morson BC, et al. Precancer and cancer in extensive ulcerative colitis: findings among 401 patients over 22 years. Gut 1990;31:800-6.

3 Schneider A, Stolte M. Clinical and pathomorphological findings in patients with colorectal carcinoma complicating ulcerative colitis. Z Gastroenterol 1993;3:192-7.

4 Van der Woude CJ, Kleibeuker JH, Jansen PLM, et al. Chronic inflammation, apoptosis and (pre)-malignant lesions in the gastro-intestinal tract. Apoptosis 2004:9:123-30

5 Jaiswal M, LaRusso NF, Gores GJ. Nitric oxide in gastrointestinal epithelial cell carcinogenesis: linking inflammation to oncogenesis. Am J Physiol 2001;281:G626-34.

6 Bantel H, Berg C, Vieth M, et al. Mesalazine inhibits activation of transcription factor NF-kappaB in inflamed mucosa of patients with ulcerative colitis. Am J Gastroenterol 2000;12:3452-7.

7 van der Woude CJ, Jansen PL, Tiebosch AT, et al. Expression of apoptosisrelated proteins in Barrett's metaplasia-dysplasia-carcinoma sequence: a switch to a more resistant phenotype. Hum Pathol 2002;33:686-92.

8 Jaiswal M, LaRusso NF, Shapiro RA, et al. Nitric oxide-mediated inhibition of DNA repair potentiates oxidative DNA damage in cholangiocytes. Gastroenterology 2001;120:190-9.

9 Tsuiii M, Dubois RN. Alterations in cellular adhesion and apoptosis in epithelial cells overexpressing prostaglandin endoperoxide synthase 2. Cell 1995;83:493-501.

10 Vogelstein B, Fearon ER, Hamilton SR, et al. Genetic alterations during colorectal-tumor development. N Engl J Med 1988;319:525-32.

11 Burmer GC, Levine DS, Kulander BG, et al. C-Ki-ras mutations in chronic ulcerative colitis and sporadic colon carcinoma. Gastroenterology 1990;99:416-20

12 Itzkowitz SH, Greenwald B, Meltzer SJ. Colon carcinogenesis in inflammatory bowel disease. Inflamm Bowel Dis 1995;1:142.

13 Burmer GC, Rabinovitch PS, Haggitt RC, et al. Neoplastic progression in ulcerative colitis: histology, DNA content, and loss of a p53 allele. Gastroenterology 1992;103:1602-10.

14 Fogt F, Vortmeyer AO, Goldman $\mathrm{H}$, et al. Comparison of genetic alterations in colonic adenoma and ulcerative colitis-associated dysplasia and carcinoma. Hum Pathol 1998:29:131-6.

15 Fogt F, Urbanski SJ, Sanders ME, et al. Distinction between dysplasiaassociated lesion or mass (DALM) and adenoma in patients with ulcerative colitis. Hum Pathol 2000;3:288-91.

16 Riddell RH, Goldman H, Ransohof DF. Dysplasia in inflammatory bowel disease: standardised classification with provisional clinical applications. Hum Pathol 1983;14:931. 